\title{
Article \\ Performance Analysis of a Magnetorheological Shock Absorber Prototype Designed According to a Quasi-Static No-Slip Model
}

\author{
Danilo D'Andrea ${ }^{1}$, Giacomo Risitano ${ }^{1}$ (I) and Lorenzo Scappaticci ${ }^{2, *}$ \\ 1 Department of Engineering, University of Messina, Contrada di Dio (Sant'Agata), 98166 Messina, Italy; \\ dandread@unime.it (D.D.); grisitano@unime.it (G.R.) \\ 2 Sustainability Engineering Department, Guglielmo Marconi University, via Plinio 44, 00193 Rome, Italy \\ * Correspondence: 1.scappaticci@unimarconi.it;
}

Citation: D'Andrea, D.; Risitano, G.; Scappaticci, L. Performance Analysis of a Magnetorheological Shock Absorber Prototype Designed According to a Quasi-Static No-Slip Model. Actuators 2021, 10, 13. https://doi.org/10.3390/act10010013

Received: 15 December 2020 Accepted: 8 January 2021 Published: 11 January 2021

Publisher's Note: MDPI stays neutral with regard to jurisdictional clai$\mathrm{ms}$ in published maps and institutional affiliations.

Copyright: (C) 2021 by the authors. Licensee MDPI, Basel, Switzerland. This article is an open access article distributed under the terms and conditions of the Creative Commons Attribution (CC BY) license (https:// creativecommons.org/licenses/by/ $4.0 /)$.

\begin{abstract}
The aim of this paper is to investigate the limits of the quasi-static, no-slip approach when modeling the activation of magnetorheological (MR) devices. A quasi-static model is implemented to define the hydraulic and magnetic characteristics of an MR damper prototype. Then, an FE (Finite Element) magnetic simulation activity is carried out to validate theoretical findings, and an optimization procedure is carried out to adjust nominal geometry to actual application. Furthermore, a prototype is realized re-using the maximum number of components that constitute the existing conventional shock absorber. Finally, experimental tests at bench stands are performed. The predictable results demonstrate that neglecting the transient slipping effects, the Force-Velocity performance of the device is correlated with the model findings only for low current intensities acting in the magnetic circuit.
\end{abstract}

Keywords: magnetorheological damper; smart materials; shock absorber; FE simulation

\section{Introduction}

In a motorcycle, the suspensions are the set of parts that connect the sprung and unsprung masses, allowing relative motion. The unsprung masses are all those elements connected to the ground-tires, rims, the brake system, and the parts of the suspension integral with them. Instead, all the components above the suspension belong to the sprung masses, such as the chassis, engine, fairing, and driver [1]. The role of the suspension system is crucial in the vehicle design, as it performs different tasks, and its performance requirements are often conflicting: it guarantees the contact between the vehicle tires and road while isolating the vehicle body from the vibrations due to the road roughness [2].

Mechanically, a conventional shock absorber is composed of a spring and a central body that is designed as a hydraulic circuit to ensure a certain damping effect; the dynamic driving behavior can be customized by adjusting the fluid passage sections when the vehicle is stationary. When setting the suspension of a vehicle, it is necessary to satisfy different requirements such as driving comfort and good tire grip [1]. Using traditional hydraulic shock absorbers, a compromise choice must be found between comfort and safety needs; comfort riding often requires a plush, underdamped shock absorbers setting, while the search for grip and traction mostly suggests overdamped characteristics.

Magnetorheological (MR) fluids devices applied in the field of vehicle suspensions allow dynamically adjusting damping characteristics, exploiting the physical characteristics of the MR fluids [3-5] so as to overcome the constraint of a compromise setting. Discovered by Jacob Rabinow [6], MR fluids consist of micron-sized, magnetically polarizable ferrous particles suspended in a carrier fluid such as oil. MR fluids are smart materials, whose chemical-physical characteristics can vary in a controlled way, depending on the intensity of the magnetic field. Different design solutions of an MR damper can be chosen, according to the "fluid activation" strategy (direct shear-see Figure 1-or pressure-driven flow). 


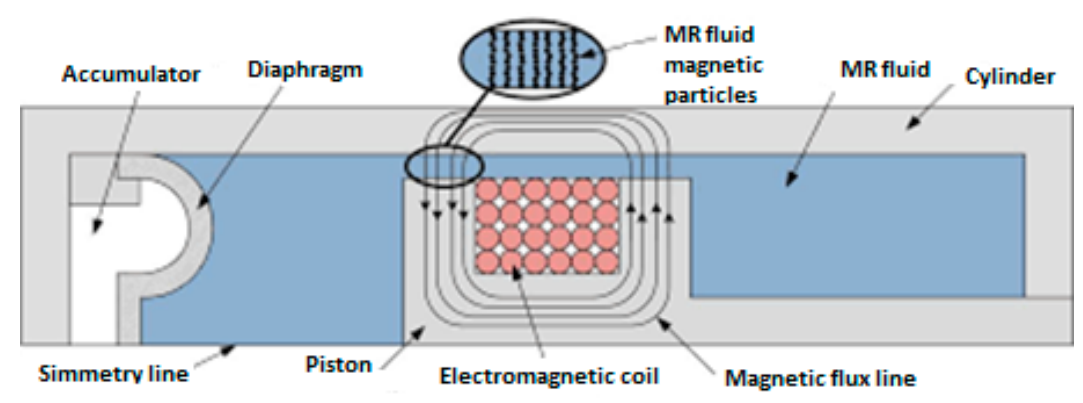

Figure 1. The Direct Shear activation scheme for an application of magnetorheological (MR) fluids for automotive shock absorbers.

The MR devices are mainly used in the civil field [7-9] for the control of structural vibrations, in the automotive field [10-12], as well as some uses in the industrial field [13,14]. $\mathrm{Li}$ et al. [15] developed and tested a steering damper for motorcycle use, also taking into consideration the ease of assembly. The device by Zhang et al. [16] is equipped with a piston with an internal bypass valve and a permanent magnet. The valve serves to prevent the blockage of the fluid in case of high currents applied, while the magnet guarantees minimum safety magnetization and a wide dynamic range.

An innovation in the motorcycle field is reported by Wang et al. [17] which introduced a winding integral with the shock absorber cylinder for automatic detection of the piston position (IRDS). This system is interesting, as the piston winding simultaneously activates the MR fluid and acts as a displacement sensor.

Again, with regard to control systems, Metered et al. [18] developed a neural networkbased one. These allow a low energy demand, long service life, and a minimal use of the sensors, making it the most convenient system in economic terms. Spelta et al. [12] reported the study of a control system for semi-active suspension applied to a dirt motorcycle. Regarding shock absorbers with permanent magnets, Du et al. [19] carried out studies on the flow losses in the magnetic circuit, indicating significant differences between experimental results and modeling and specifying the appropriate corrective factors for the case under consideration. Chen et al. [20] published studies on an MR shock absorber for vehicles, which were equipped with self-sensing speed and the ability to recover the mechanical energy of vibration with transformation into electricity. The main advantages are savings in terms of costs, weight, dimensions, and, of course, energy.

In this paper, a quick technical approach was used to define geometrical dimensions of the MR shock absorber, through which the minimum and maximum damping forces were determined. Subsequently, the hydraulic and magnetic circuits were dimensioned to guarantee the above forces. As a performance requirement, it was established that a semi-active damper should perform a wide range "Force vs. Velocity" (F-V) diagram that is superimposable to that of a conventional high-end SuperSport shock absorber, i.e., equipped with high and low speed adjustment, both for compression and rebound. This functional prerogative represents the most challenging objective since, within the full range of hydraulic adjustments available, the traditional shock absorbers for SuperSport applications show performances which, to date, are considered as state of the art. Moreover, we also decided to keep the overall dimensions of the MR prototype unchanged with reference to the traditional device. The prototype building approach was based on the idea of re-using the maximum number of components that constitute the existing traditional passive device. In this way, any implementation on the motorcycle could take place without any mechanical intervention on the frame and suspension, at a minimal cost.

The aim of this paper is to investigate the limits of the quasi-static, no-slip approach when modeling the activation of the MR fluid of devices that must guarantee high performance for a wide spectrum of acting forces, such as in the case of shock absorbers for motorcycle use. The quasi-static approach to modeling the activation of a MR fluid, if the slip effect is neglected, is lean and essentially requires the design of the induced magnetic 
field, but what is the downside? The experiment described in the paper demonstrates that the range of use in which the device offers the required damping forces is predictable for low current intensities acting in the magnetic circuit. The results could be useful to understand the accuracy of the required mathematical model as a function of the desired $\mathrm{F}-\mathrm{V}$ response, and this is a novelty in the field.

Therefore, the present paper is basically an overview on the whole activity, i.e., from mathematical models to the experimental comparative testing at bench stands, highlighting the limits of the quasi-static approach with no slip.

First, a quasi-static axisymmetric model is implemented in Matlab to obtain geometrical characteristics of the gap and to design the magnetic circuit. Therefore, a magnetic simulation activity is carried out to validate theoretical findings. Furthermore, an optimization procedure is carried on adjusting nominal geometry to actual application. Finally, experimental tests are proposed.

\section{Materials and Methods}

As hinted in Section 1, the philosophy of the present work is proposing a global view approach for MR dampers design: from the performance requirements to a prototype built by re-engineering a passive shock absorber, from the numerical modeling of the magnetic field to the choice of the material, until operational validation. The main activities can be summarized as following:

- Determination of the gap geometry: By means of geometric parameters, estimate the force from the device as a function of the fluid volume stimulated by the magnetic field.

- Calculation of the total reluctance of the equivalent magnetic circuit: By means of the definition of the equivalent RL circuit, this activity returns an estimate of the number of windings of the wire.

- Calculation of the winding configuration: According to time response issues, define the configuration of the winding.

- Design optimization by means magnetic simulation: Based on the theoretical findings, Finite Element Analysis (FEA) is employed for numerical modeling of magnetic field and stresses distribution according to the chosen geometry. Geometry itself is optimized to ensure functionality

- Manufacturing of the prototype: the MR prototype is manufactured starting from components of a traditional, passive, shock absorber. A new piston is realized, and the main cylinder housing in which the piston is engaged is replaced to ensure the closure of the magnetic field. Once the MR device is assembled, it is tested under typical working conditions.

- Final operational validation: bench tests are performed at different current intensities (including challenging limits) acting in the RL circuit, and a comparative analysis with the passive traditional shock absorber is proposed.

\subsection{Design of the MR Damper}

The functional characteristics of a hydraulic shock absorber for high-end SuperSport purpose, such as the F-V diagram were used as a reference. So, a characterization of a traditional shock absorber available on the market (Matris M46R) was first performed on the test bench (Figure 2). The reference to a specific product does not make the work lose generality, since the top-of-the-range products of each manufacturer show similar characteristics. Moreover, with a view to re-engineering an MR shock absorber exploiting a high number of existing components taken from a traditional device, the geometric dimensions related to the cylinder housing and the useful stroke were considered settled. 


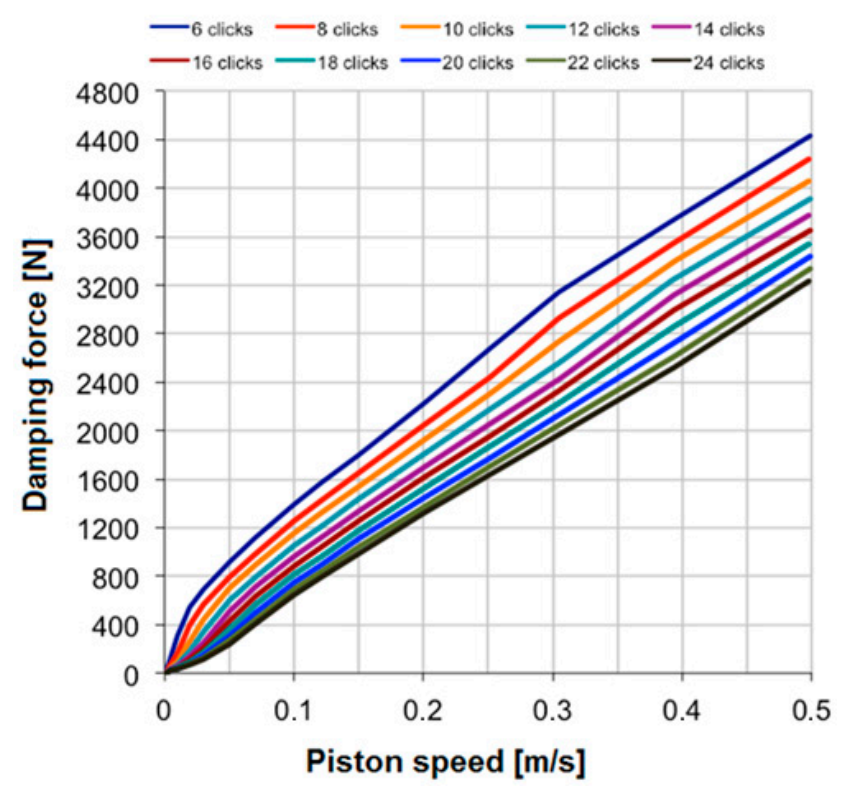

Figure 2. "Force vs. Velocity" (F-V) characteristic curves of the Matris M46R in compression. The clicks are an index of the hydraulic brake, and considering a single piston speed, it is possible to observe the increase in the damping force and therefore in the damping coefficient, which occurs with the passage from the hydraulic open condition ( 24 clicks) to the condition of closed hydraulics (six clicks).

The nominal performance forces for the MR prototype were established as follows. Referring to the F-V curves of the conventional shock absorber (see Figure 2), at maximum speed, in the condition of fluid activated with maximum current intensity, the MR shock absorber should offer a force equal to the traditional shock absorber with the hydraulic closed. Instead, the force required in the condition of deactivated fluid (zero current) should be equal to that of the conventional device with open hydraulic condition. Assuming a maximum piston velocity equal to $V_{M A X}=0.5 \mathrm{~m} / \mathrm{s}$, the force that the magnetic shock absorber should exert in the hydraulic closed condition is $F_{O N} M a x=4431 \mathrm{~N}$ and in the condition of hydraulic open, it is $F_{\text {OFF }}$ Min $=3235 \mathrm{~N}$.

Once the performance requirements are established, a Design Algorithm (DA) was implemented in Matlab [21] exploiting the findings of a quasi-static axisymmetric model [22].

Essentially, that DA represents the sizing of the magnetic circuit as a function of the desired output forces and of the physical characteristics of the materials. The DA worked with "if" and "while" loops (see Figure 3) and proposed the geometry of the gap as a function of the maximum force required and minimum volume of activated fluid, and it iterates the process for the quantities definition to obtain the shortest magnetization time of the winding. The DA received nine constants as input and three parameters to be iterated and returned seven values that completely define the gap, piston geometry, and winding characteristics as well as the F-V characteristics at maximum current intensity and zero current.

Other input data were the magnetic permeability values of the MR fluid and the steel, which were necessary to characterize the magnetic circuit, the maximum current intensity applicable to the winding, the resistivity of the copper, and the curves $B=B(H)$ and $\tau_{0}=\tau_{0}(\mathrm{H})$ related to the fluid. In addition, other parameters were used such as the diameter of the copper wire of the winding, the number of wire passes, and the internal diameter of the piston. 


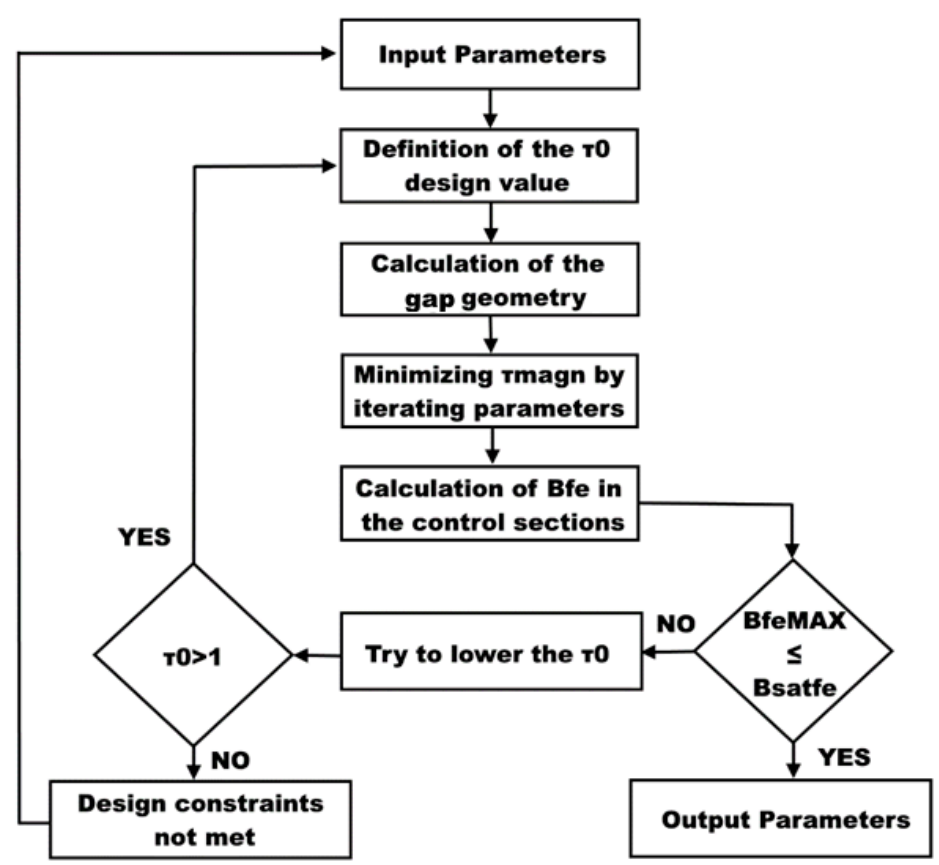

Figure 3. Block diagram of the Design Algorithm (DA).

The geometry of the gap depends on the piston geometry, magnetic properties of the materials, and geometry of the gap. All the inputs and outputs are shown in Table 1.

Table 1. Input and output data.

\begin{tabular}{ccc}
\hline Name & Symbol & Unit \\
\hline Inputs & & $\mathrm{mm}$ \\
\hline Internal diameter of the cylinder & Dcint & $\mathrm{mm}$ \\
External diameter of the cylinder & Dcest & $\mathrm{mm}$ \\
Piston stroke & $c$ & $/$ \\
Relative magnetic permeability of steel & $\mu_{r f e}$ & $\mathrm{H} / \mathrm{m}$ \\
Absolute magnetic permeability of the fluid & $\mu_{a f l}$ & $\mathrm{H} / \mathrm{m}$ \\
Magnetic permeability in vacuum & $\mu_{0}$ & $\Omega^{*} \mathrm{~m}$ \\
Resistivity of copper & $\rho$ & $/$ \\
Constant for minimum volume activated & $\alpha$ & $\mathrm{A}$ \\
Maximum current intensity & $I_{\text {max }}$ & $\mathrm{mm}$ \\
Solenoid diameter & $D_{\text {sol }}$ & $\mathrm{mm}$ \\
Wire diameter & $\Phi_{\text {wire }}$ & $/$ \\
Number of wire passes & $N_{p a s s}$ & $\mathrm{~mm}$ \\
Outputs & & $\mathrm{mm}$ \\
\hline Volume of MR fluid activated & $V_{\text {min }}$ & $\mathrm{mm}$ \\
Length of gap & $g$ & $\mathrm{~mm}$ \\
Gap thickness & $h$ & $\mathrm{~mm}$ \\
Gap width & $w$ & $\mathrm{~mm}$ \\
Piston length & $L_{p i s t}$ & $/$ \\
Piston diameter & $D_{p}$ &
\end{tabular}

In order to obtain a short time magnetic response in the gap [23], an economic and easily workable ferromagnetic material (AISI 1018) was chosen for the piston prototype. According to the experimental $\mathrm{B}(\mathrm{H})$ curve of the AISI 1018 steel, it was set as the limit value for the magnetic induction $B_{s a t} F e=1.5 \mathrm{~T}$, which is the magnetic field saturation.

The $B_{\text {sat }} \mathrm{Fe}$ value was a constraint condition in the DA and acted as a control parameter to check the piston geometry. Whenever the design flow did not lead to a geometry that 
allows compliance with the saturation limits in the gap, the tangential stress value $\tau_{0}$, that is the nominal $\tau$ obtainable by magnetizing the MR fluid in the gap, was decreased.

In the block called "Calculation of the gap geometry", the direct shear (see Figure 1) activation mode for MR fluids was implemented within a while loop; exiting the while loop was allowed if the damping force in the activated fluid condition $F_{\text {out } O N}$ exceeded the $F_{\text {ONMax }}$, which is the maximum exerted damping force for the traditional device experimentally observed. To obtain this result, the height of the gap g was increased in steps of a tenth of a millimeter.

The calculation of the minimum volume of activated fluid $V_{\min }$ occurred with following equation [24]:

$$
V_{\min }=\alpha *\left(\frac{\eta}{\tau_{y}^{2}}\right) *\left(\frac{F_{o n}}{F_{o f f}}\right) * F_{o n} * V_{\max }
$$

where the $V_{\min }$ becomes a reference value $\left(V_{\min }\right.$ ref $)$, which is used when changing the $\tau_{0}$ to calculate the initial $\mathrm{V}_{\min }$ according to the following equation:

$$
V_{\text {minstart }}=V_{\min r e f} *\left(\frac{\tau_{0 \max }^{2}}{\tau_{0}^{2}}\right) .
$$

In the first geometry definition attempt, all the values were calculated according to the $V_{\min }$ starting point. Subsequently, having a first attempt geometry of the gap available, at the end of each cycle, $V_{\min }$ was recalculated according to (1) to be reused in the next step, as long as $F_{\text {out }}$ ON remained below the $F_{O N M a x}$.

Having to vary the response of the shock absorber in relation to the speed with which it is compressed, it is important that the fluid magnetizes to the desired value in a short time. Since the fluid needs a few tens of milliseconds to react to the applied magnetic field, it follows that its response times depends on the time constant $\left(\tau_{m g}\right)$ of the equivalent RL electric circuit (see Figure 4).

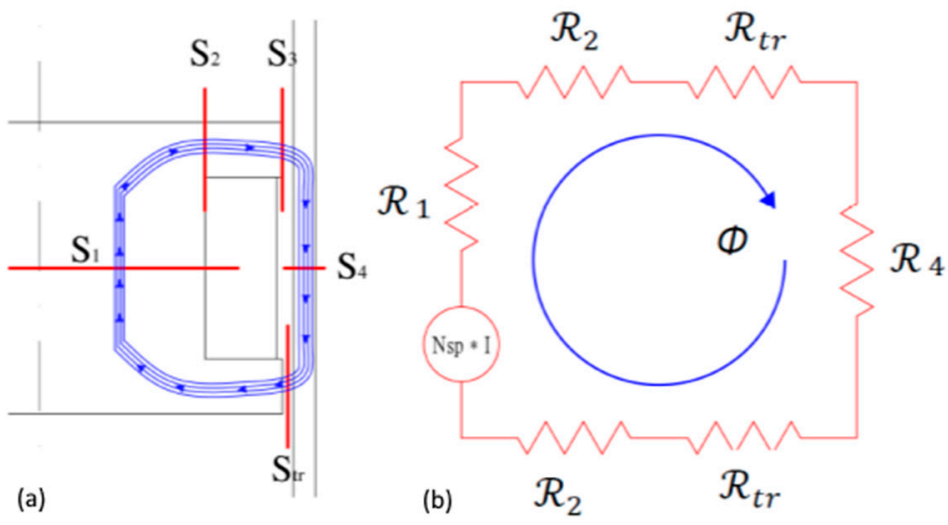

Figure 4. Magnetic circuit: (a) control sections, (b) equivalent circuit.

\subsection{Determination the $\tau_{m g}$}

Inside the block "Choice of the configuration of the parameters to be iterated with the criterion of the minor $\tau_{m g}$ ", the magnetic circuit was modeled. In compliance with the tangential stress required in the fluid $\left(\tau_{0}\right)$ and the necessary $B_{f l}$ value, and given the geometry of the gap, the magnetic flow $\phi$ that must take place in the magnetic circuit defined by the piston, gap, and cylinder housing is univocally defined. By the reluctance method, one can define the number of turns $N_{s p}$ :

$$
N_{s p} * I_{\max }=R_{t o t} * \phi
$$

where $I_{\max }$ is the maximum intensity current and $R_{t o t}$ is the total reluctance. 
The schematic representation of the magnetic circuit (see Figure 4), which is necessary to define the reluctances of the actual application, was also revised considering the observations in [25].

Reluctance $R_{1}$ and section $S_{1}$ relate to the central body of the piston, while $R_{2}$ and sections $S_{2}$ and $S_{3}$ relate to the piston wings. $R_{t r}$ and $S_{t r}$ relate to the MR fluid, and $R_{4}$ and $S_{4}$ refer to the cylinder housing.

$$
\begin{gathered}
S_{1}=\frac{\pi}{4} * D_{\text {sol }}^{2} \\
S_{2}=\pi * D_{\text {sol }} * g \\
S_{3}=2 \pi * R_{\text {pist }} * g \\
S_{t r}=1.05 * S_{3} \\
S_{4}=\frac{\pi}{4}\left(D_{\text {cest }}^{2}-D_{\text {cint }}^{2}\right)
\end{gathered}
$$

To calculate the reluctance of the piston wings that have a variable section from $S_{2}$ to $S_{3}$, the reluctance expressed in infinitesimal terms (9) was integrated by $D_{\text {sol/2 }}$ to $R_{\text {pist }}$, which is based on the heat conduction model through the cylindrical wall.

$$
\begin{gathered}
d R=\frac{d r}{\mu_{a f l} * 2 \pi * r * g}=>R=\int_{R_{i}}^{R_{e}} \frac{d r}{\mu_{a f l} * 2 \pi * r * g} \\
R_{1}=\frac{\frac{N_{s p}}{N_{\text {pass }}} * \phi_{\text {wire }}+g}{\mu_{a F e} * S_{1}} \\
R_{2}=\frac{1}{\mu_{a f l} * 2 \pi * g} * \ln \frac{2 R_{\text {pist }}}{D_{\text {sol }}} \\
R_{t r}=\frac{h}{\mu_{a f l} * S_{t r}} \\
R_{4}=\frac{\frac{N_{s p}}{N_{\text {pass }}} * \phi_{\text {wire }}+g}{\mu_{a F e} * S_{4}}
\end{gathered}
$$

As shown, $N_{s p}$ appears in (10). Total reluctance depends on physical constants (absolute magnetic permeability of steel and MR fluid), and the geometric values (lengths $l$ and areas of sections $S$ of the circuit) are all known or calculable, except for the number of turns of the winding; therefore, Equation (3) can be rewritten by specifying $N_{s p}$.

Considering:

$$
R_{t o t}=R_{1}+2 R_{2}+2 R_{t r}+R_{4}
$$

One can obtain:

$$
N_{s p}=\frac{\phi(g * A+B)}{(I-\phi) * \phi_{\text {wire }} * \frac{A}{N_{\text {pass }}}}
$$

where $A$ and $B$ are equal, respectively:

$$
\begin{gathered}
A=4\left(\frac{1}{\mu_{a F e} * \pi * D_{\text {sol }}^{2}}+\frac{1}{\mu_{a F e} * \pi *\left(D_{\text {cest }}^{2}-D_{\text {cint }}^{2}\right)}\right) \\
B=\frac{\ln \left(2 R_{\text {pist }} / D_{\text {sol }}\right)}{\mu_{a F e} * \pi * g}+\frac{h}{1.05 * \mu_{a f l} * \pi * R_{\text {pist }} * g} .
\end{gathered}
$$

Once the winding magnetization time was determined, an RL equivalent circuit was resolved to determine the length of the wire:

$$
L_{\text {wire }}=\pi * N_{s p} *\left(D_{\text {sol }}+N_{\text {pass }} * \phi_{\text {wire }}\right) .
$$


Since the piston geometry and the winding characteristics are all determined, therefore, $B_{F e}$ was calculated in the control sections $S_{1}, S_{2}$, and $S_{4}$. In addition, since the magnetic flux is constant, in correspondence of section $S_{3}$, the maximum magnetic induction value of the ferromagnet was obtained. If its value was less than the $B_{\text {sat } F e}$ limit, the design process was finished; otherwise, the algorithm reduced the $\tau_{0}$ and restarted from the determination of the gap geometries.

\subsection{FEA and Optimization}

To validate the theoretical findings, a magnetic FE analysis was performed. A twodimensional axisymmetric model was implemented in Ansys. According to the Direct Shear activation (Figure 2), an FE model (Figure 5) was designed to evaluate the magnetic field of the MR fluid in the gap. To model the magnetic properties of the various materials, which were subsequently assigned to the appropriate areas of the model, the $\mathrm{B}(\mathrm{H})$ curve of the MR fluid was introduced, while for copper, insulation resin, and steel, the relative magnetic permeability $\mu$ was considered.

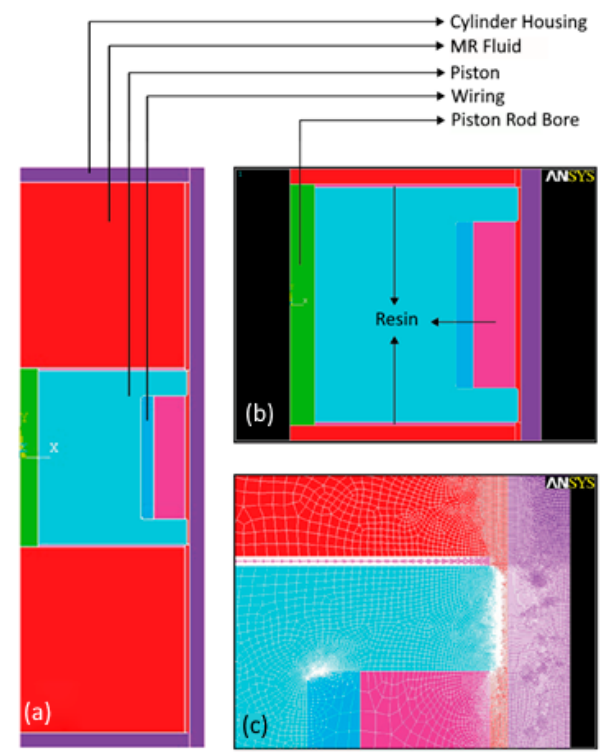

Figure 5. (a) Two-dimensional (2D) axisymmetric Finite Element (FE) model, (b) Particular of the piston, (c) A detail of the mesh.

The magnetization curve of AISI 1018 steel (cylinder housing), Fe 360 steel (piston), and MR fluid were implemented by points in the pre-processing phase of the analysis. The model consisted of about 91,000 nodes and 35,000 elements (PLANE53 of Ansys library). Boundary conditions were set as amagnetic for the outer regions.

Simulation activity allowed us also to estimate the shear stress $\tau$ to be used in the direct shear model for the calculation of the force applied and to check that the magnetic induction values in the steel parts did not exceed the imposed limit.

The DA of the MR shock absorber was performed by acting on the parameters to be iterated (Table 1) and on the $B_{s a t} F e$ magnetic induction limit.

A first analysis was carried out by setting $B_{\text {sat } F e}=1.4 \mathrm{~T}$, keeping its constraint control limit equal to $1.5 \mathrm{~T}$. The first run of the DA with the input data values shown in Table 1 did not produce satisfying results; the magnetic induction values in the section $S_{4}$, i.e., the cross-section of the shock absorber cylinder housing, exceeded the control limits. Since $S_{4}$ is constant and univocally determined by the internal and external diameters of the cylinder, the input data were varied, increasing the $D_{\text {cest }}$ diameter. By performing the DA, the solution shown in Table 2 was obtained. 
Table 2. Program output data.

\begin{tabular}{ccc}
\hline Parameter & Value & Unit \\
\hline$\tau_{0}$ & 35.7 & $\mathrm{kPa}$ \\
$D_{\text {sol }}$ & 24 & $\mathrm{~mm}$ \\
$g$ & 4.8 & $\mathrm{~mm}$ \\
$N_{\text {pass }}$ & 3 & $/$ \\
$h$ & 0.3 & $\mathrm{~mm}$ \\
$\phi_{\text {wire }}$ & 0.57 & $\mathrm{~mm}$ \\
\hline
\end{tabular}

However, with these geometrical parameters, the total length of the piston exceeded the axial overall dimension available, which is equal to $25 \mathrm{~mm}$. Therefore, some input parameters were varied, as shown in Table 3.

Table 3. New input values for sizing.

\begin{tabular}{ccc}
\hline Parameter & Value & Unit \\
\hline$D_{\text {sol }}$ & $26-27-28$ & $\mathrm{~mm}$ \\
$D_{\text {cest }}$ & 51 & $\mathrm{~mm}$ \\
$B_{\text {sat fe }}$ & 1.4 & $\mathrm{~T}$ \\
$N_{\text {pass }}$ & $5-8-10$ & $/$ \\
$\phi_{\text {wire }}$ & 0.57 & $\mathrm{~mm}$ \\
\hline
\end{tabular}

To limit the piston axial length, both the number of passages $\left(N_{\text {pass }}\right)$ and the diameter of the solenoid were considered. The diameter of the wire has a significant influence only on the resistance, so it was set equal to $\phi$ wire $=0.57 \mathrm{~mm}$.

The magnetic analysis solution showed high induction values in the control section $S_{2}$ and in some parts of the cylinder housing (see Figure 6); moreover, we noticed a difference of about $0.25 \mathrm{~T}$ with respect to the average values calculated by the DA.

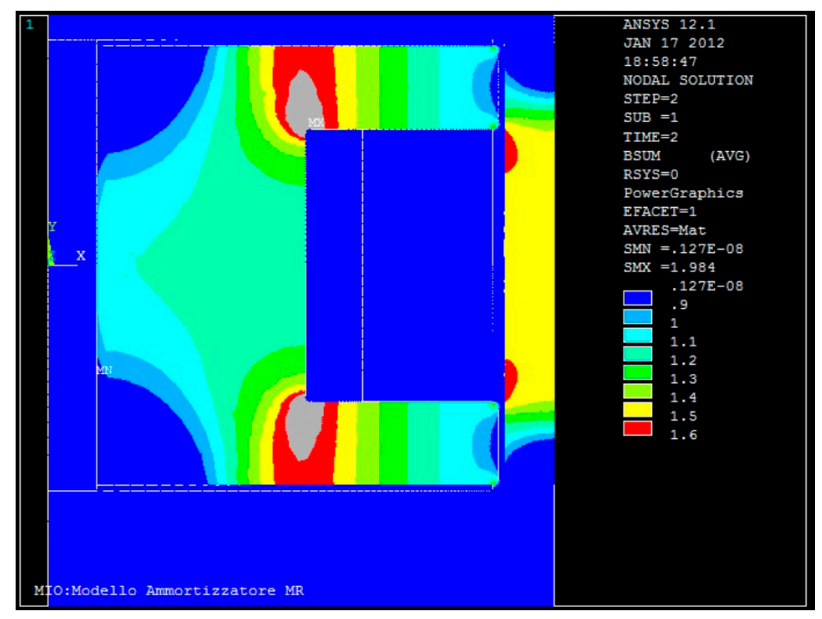

Figure 6. FE analysis of a solution that exceeds the induction limits.

The variation of the magnetic induction was further investigated by varying only one parameter at a time. Magnetic induction deriving from the dimensions chart in Table 3 was explored, considering $N_{\text {pass }}$ values of 10,12, and 15 and finding a slight deterioration of the magnetic field and a much more marked increase in terms of magnetization time. These trends suggested keeping lower the number of passages $N_{\text {pass }}$. By fixing the number of passages $N_{\text {pass }}=8, B_{f e}$ was analyzed by varying $D_{s o l}$. As $D_{\text {sol }}$ increased, the magnetic induction $B_{f e}$ estimated by DA decreased in the control sections $S_{1}$ and $S_{4}$, increased in $S_{3}$, and remained approximately unchanged in $S_{2}$. The same trends were observed from the 
results of the magnetic analysis (see Figure 7), which stands at average values greater than 0.2-0.3 T. Therefore, $B_{\text {sat limit fe }}=1.2 \mathrm{~T}$ was set.
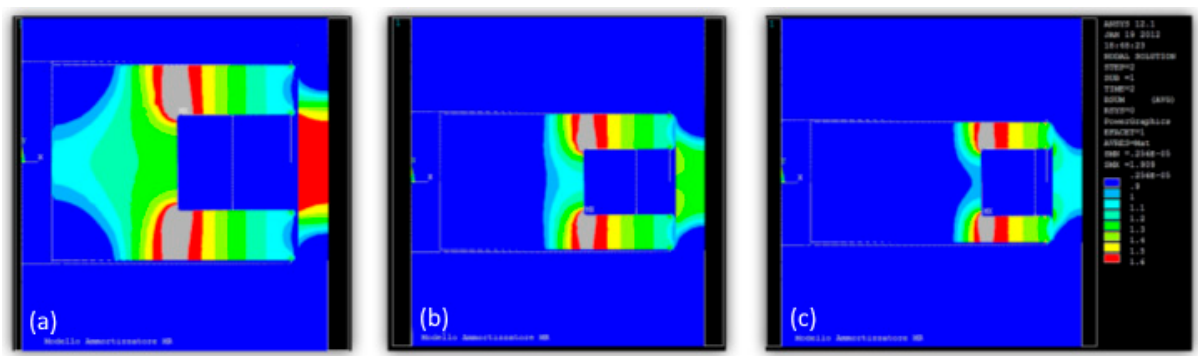

Figure 7. Comparison between FE analysis with different solenoid diameters $\left(D_{\text {sol }}\right)$ : (a) $26[\mathrm{~mm}]$; (b) $30[\mathrm{~mm}]$; (c) $34[\mathrm{~mm}]$.

The trends of some fundamental geometric dimensions and physical characteristics as a function of the $N_{\text {pass }}$ and $D_{\text {sol }}$ parameters can be deduced from the data listed in Table 4 .

Table 4. Output data as $N_{\text {pass }}$ and $D_{\text {sol }}$ vary.

\begin{tabular}{ccccccc}
\hline $\boldsymbol{N}_{\text {pass }}$ & $\mathbf{h}[\mathbf{m m}]$ & $\mathbf{g}[\mathbf{m m}]$ & $\boldsymbol{\tau}_{\mathbf{0}}[\mathbf{k P a}]$ & $\boldsymbol{L}_{\text {pist }}[\mathbf{m m}]$ & $\boldsymbol{N}_{\boldsymbol{s p}}$ & $\boldsymbol{\tau}_{\mathbf{m g}}[\mathbf{s}]$ \\
\hline 5 & 0.3 & 4.2 & 38.3 & 22.1 & 120 & 0.47 \\
8 & 0.3 & 4.2 & 38.3 & 16.4 & 112 & 0.58 \\
10 & 0.3 & 4.2 & 38.3 & 14.7 & 110 & 0.86 \\
$D_{\text {sol }}[\mathrm{mm}]$ & & & & & & \\
26 & 0.3 & 4.2 & 38.3 & 16.4 & 112 & 0.58 \\
30 & 0.2 & 3.1 & 41.7 & 11.9 & 80 & 0.67 \\
34 & 0.2 & 2.3 & 43.5 & 10.3 & 80 & 0.78 \\
\hline
\end{tabular}

The solenoid diameter $D_{\text {sol }}$ exhibited the greatest influence on the magnetic induction values, while the effect of changing the number of passes mainly influenced the magnetization time. By examining the possible combinations between $D_{\text {sol }}$ variables from 30 to $36 \mathrm{~mm}$ and $N_{\text {pass }}$ from 2 to 5 , a solution was obtained only by considering $D_{\text {sol }} \geq 32$ and $N_{\text {pass }} \geq 3$. Since a least number of wire passes guarantees lower $\tau_{\mathrm{mg}}$, numerical analyses were performed keeping this constraint, fully exploiting the available space in the axial direction $L_{\text {pistMAX }}=25 \mathrm{~mm}$.

Three further cases $\left(D_{\text {sol }}=32,34,36 \mathrm{~mm}, N_{\text {pass }}=3\right)$ were investigated, and magnetic induction values were always lower than the limit of $1.5 \mathrm{~T}$, except for the internal corners of the piston where local peaks of about $1.8 \mathrm{~T}$ were noted. Given the local character of the phenomenon (see Figure 8), the results have been considered acceptable.
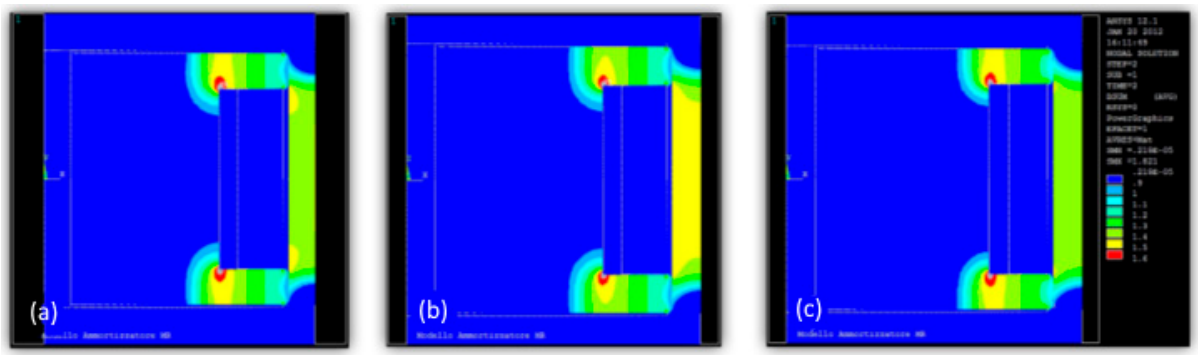

Figure 8. FE analysis with the parameter $N_{\text {pass }}=3$, which respects the induction limits: (a) $D_{\text {sol }}=32[\mathrm{~mm}]$; (b) $34[\mathrm{~mm}]$; (c) $36[\mathrm{~mm}]$.

According to the quasi-static parallel plate model, for each of these design options, the MR shock absorber showed oversized F-V curves if compared to the hydraulic shock absorber reference. The most critical data were the performance at zero current intensity 
$\left(F_{M R}\right.$ OFF $)$, since it did not allow the device to fully cover the speed field below $0.25 \mathrm{~m} / \mathrm{s}$, as shown in Figure 9.

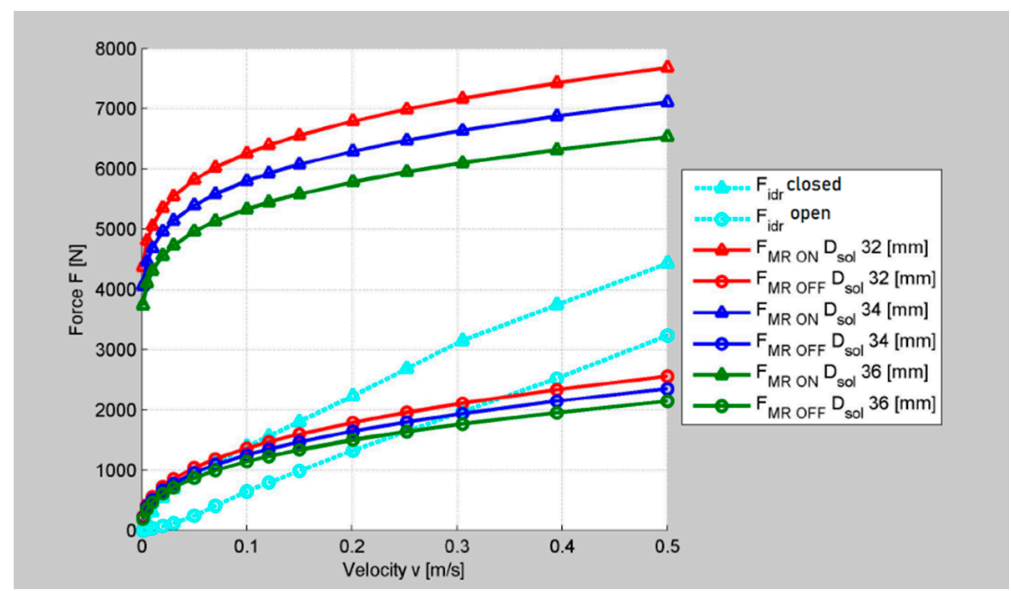

Figure 9. Comparison of the F-V curves by varying $D_{\text {sol }}$ with respect to the performance of the hydraulic shock absorber.

In order to further optimize the model, the clearance between the piston and cylinder was increased, without excessively deteriorating the performance at maximum current intensity $\left(F_{M R}\right.$ ON $)$. In this contest, geometric solutions with $D_{\text {sol }}=33,35$, and $36 \mathrm{~mm}$ were considered, also varying the gap height in steps of $0.3 \mathrm{~mm}$, which is approximately $10 \%$ of the initial value, and the gap thickness of $0.05 \mathrm{~mm}$, corresponding to a variation of $0.1 \mathrm{~mm}$ in the piston diameter. The h-g combinations that guaranteed F-V curves with the best compromise between covering the area at low speed and achieving adequate force in the activated fluid condition were obtained with $\mathrm{h}=0.3 \mathrm{~mm}$ and $\mathrm{g}=3.4 \mathrm{~mm}$ (Figure 10).

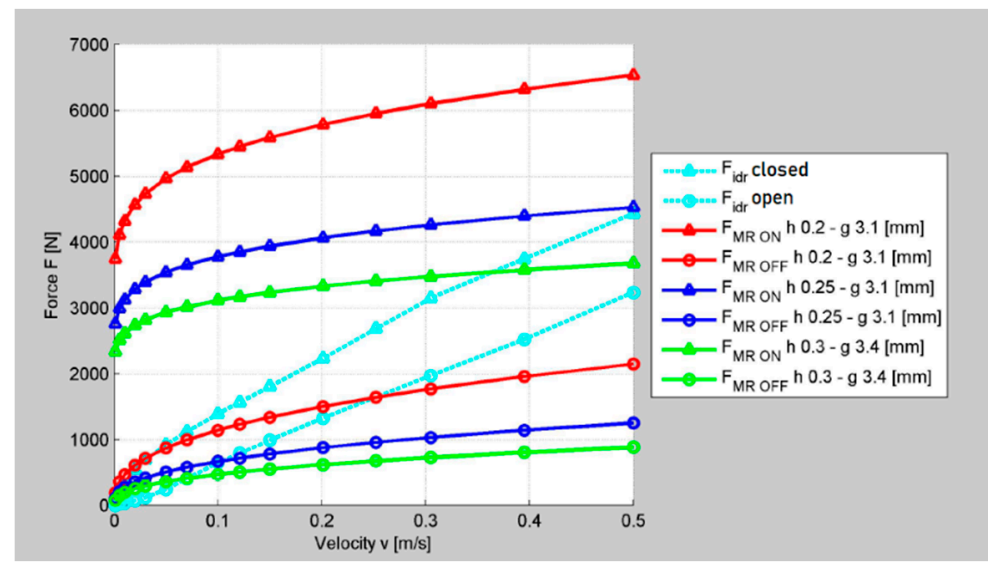

Figure 10. F-V curves when parameters $h$ and $g$ vary.

Finally, $D_{\text {sol }}=33 \mathrm{~mm}$ was considered the best compromise, since it allowed holding the magnetic induction limits, especially in the cylinder housing section (see Figure 11). 


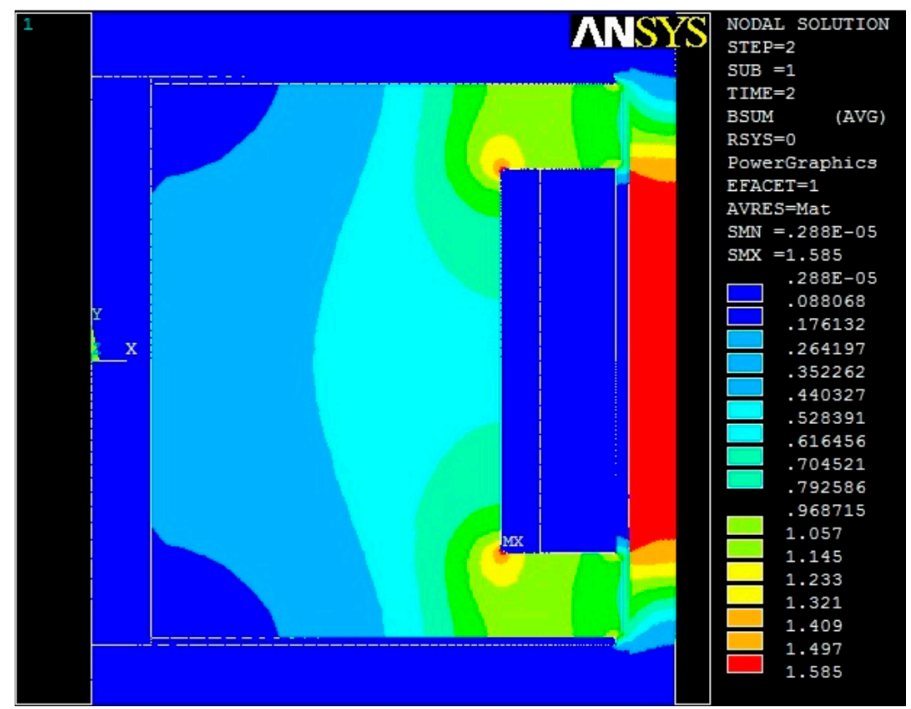

Figure 11. Result of the FE analysis with $D_{\text {sol }}=35[\mathrm{~mm}] ; \mathrm{h}=0.3[\mathrm{~mm}] ; \mathrm{g}=3.4[\mathrm{~mm}]$.

\section{Manufacturing the MR Prototype}

For the prototyping of the magnetorheological shock absorber, a hydraulic shock absorber was used, keeping unchanged most of the overall dimensions and damping characteristics. The MR shock absorber was realized maintaining the same piston rod, piston guide, and compensation tank. The main cylinder housing was replaced by a ferromagnetic one. As for the piston, the lamellar pack was removed, keeping the disc perforated to ensure the coaxiality of the new piston with the cylinder: this feature guarantees a space through which the fluid can flow and can be magnetized.

The material used for the piston is a Fe 360 steel, which was chosen for the good compromise it offers between magnetic characteristics and workability. To avoid MR fluid contact-winding and MR fluid-upper and lower surfaces of the piston, the epoxy resin produced by Dolph's was interposed as an insulator, mixing hardener, and resin with a 10:1 ratio.

The new MR piston was built in three phases:

- Realization of the piston and protections (caps);

- Realization of the wire winding; and

- Application of the resin in parallel with the assembly of the pieces.

On the upper surface, two holes were made for the winding wires. Finally, the insulating resin was applied, and the following were installed: internal spring, seal, O-ring, cylinder cap, and lower uniball (Figure 12). Figure 13 shows the fundamental dimensional parameters of the MR shock absorber.
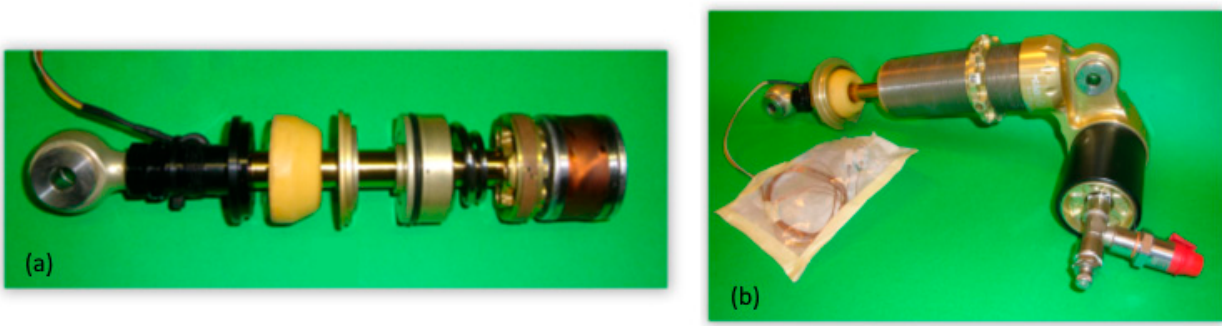

Figure 12. (a) Piston and piston rod assembly of the MR prototype damper, (b) The prototype of the MR shock absorber. 


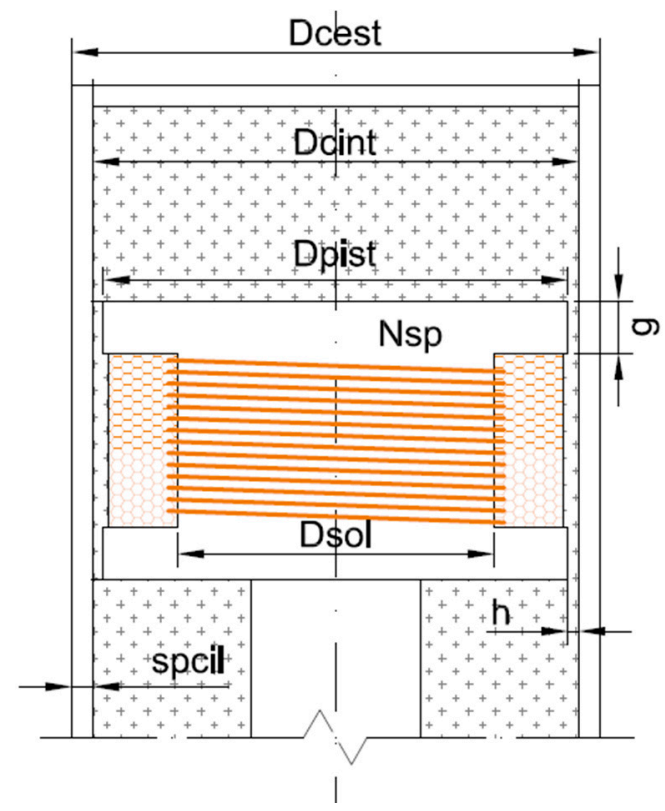

Figure 13. Dimensional parameters of the MR shock absorber.

\section{Experimental Testing}

To validate the F-V curves of the model, tests at the bench stands were performed at $300 \mathrm{~mm} / \mathrm{s}$.

The test bench is a rod-crank type with adjustable stroke up to $120 \mathrm{~mm}$ and equipped with a data logger. The test bench is equipped with a load cell with $1000 \mathrm{~kg}$ of full scale, a magnetoresistive position transducer with a stroke of $200 \mathrm{~mm}$, a contact thermocouple with a measuring range from -200 to $+400{ }^{\circ} \mathrm{C}$, and accuracy of $1^{\circ} \mathrm{C}$.

\subsection{Zero Current Intensity Tests}

At a first instance, three tests with zero current intensity for the MR shock absorber were performed, with a central time of $15 \mathrm{~s}$ and sinusoidal forcing at 1, 2, 3, and $4 \mathrm{~Hz}$ were considered (Figure 14).

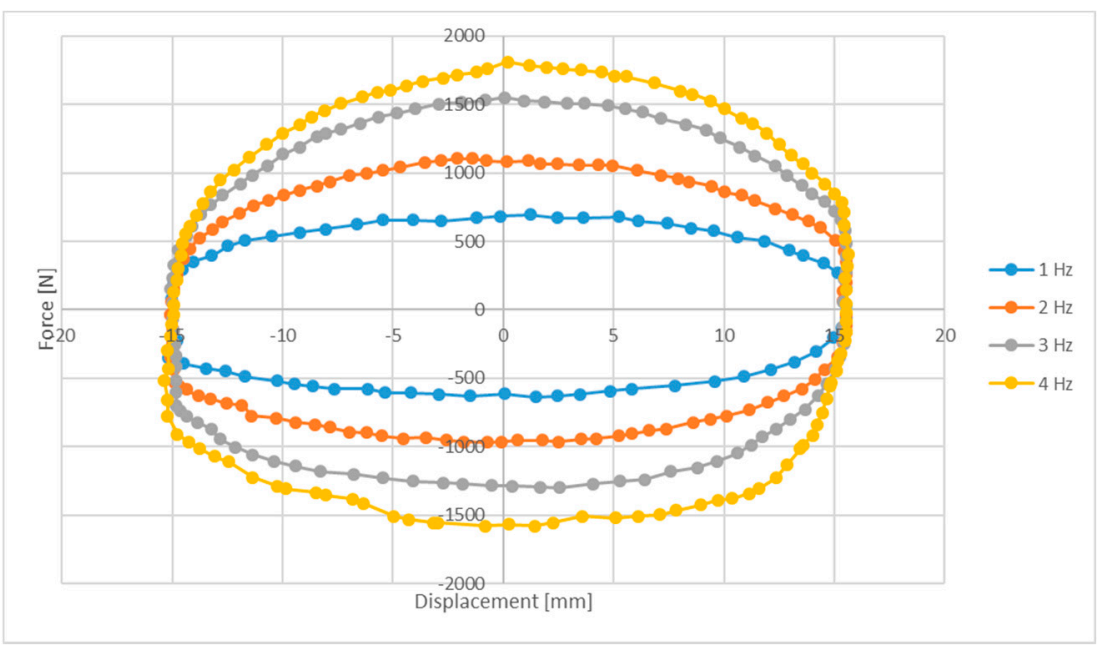

Figure 14. F-S plot of the MR shock absorber at 0 [A], with different values of forcing frequency.

\subsection{Increasing Current Tests}

In a second instance, tests at $0.5 \mathrm{~Hz}$ were performed with the current intensity varying from 0 to $1.8 \mathrm{~A}$ with an increase of $0.3 \mathrm{~A}$. Passing from 0 to $0.3 \mathrm{~A}$, it was possible to highlight 
an increase in the force exerted by the MR shock absorber, while the graphs maintained the overall shape (Figure 15).
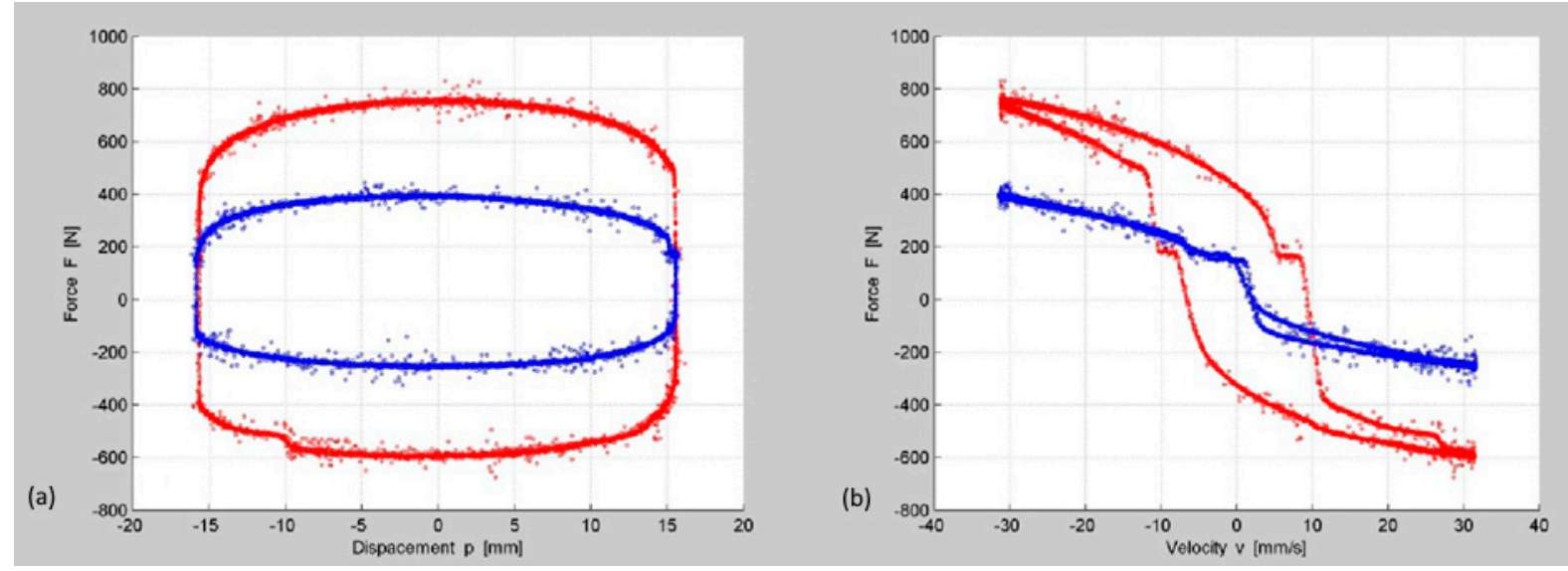

Figure 15. Comparison between run at 0 [A] (blue) and 0.3 [A] (red); (a) F-S; (b) F-V.

\section{Results and Discussion}

As it is known from the literature, such MR devices often show a non-linear behavior: in our activity, when the power supply for the magnetic circuit exceeded $0.3 \mathrm{~A}$, the trends in the F-S plane took on a pipe shape that was accentuated more and more as the current intensity increased (Figure 16).

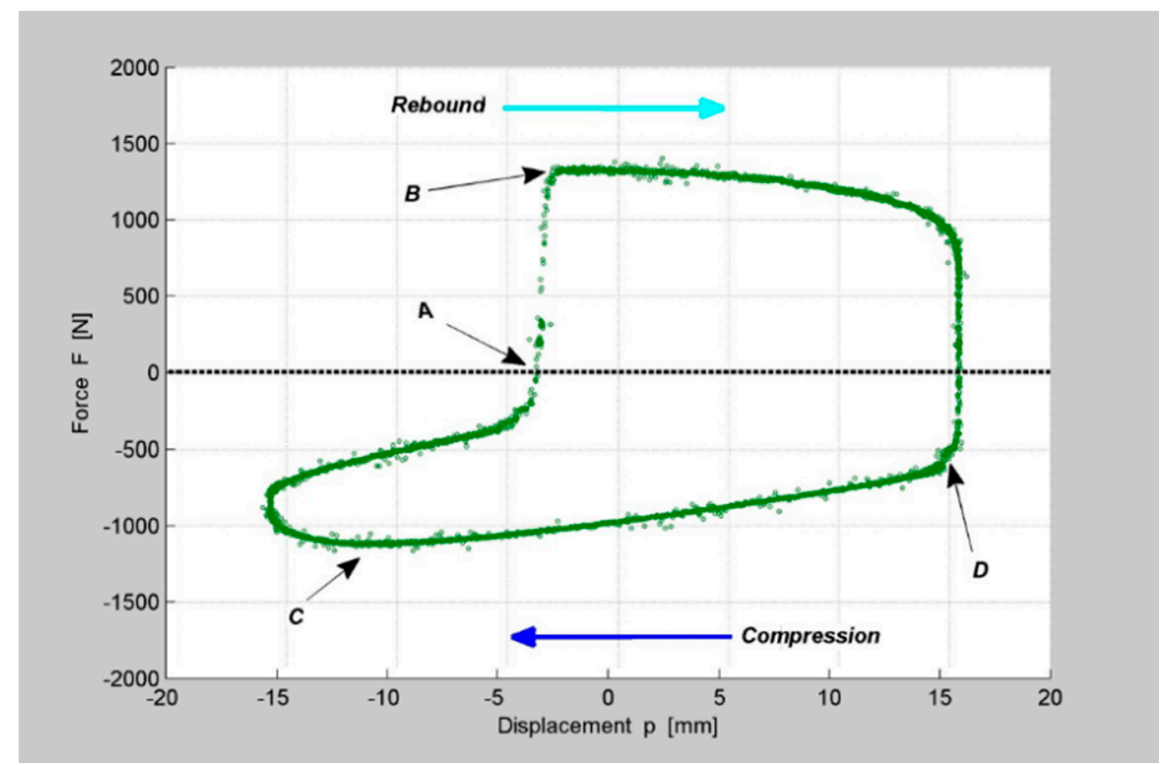

Figure 16. Pipe shaped F-S chart.

The divergence of the F-S of the MR damper from a traditional device can be explained as follows [26].

Within a certain displacement range, the ferrite particle chains act as springs that stick both to the piston and the inner housing surface, because all particle chains along the entire radius have not yet reached the sliding angle $\gamma$ [27].

The force growth due to the slip effect occurs between pre-yield and post-yield regions when ferrite chains start to slide relative to the peripheral area of the piston and relative to the outer surface of the cylinder, generating the friction force (Section $\mathrm{C}-\mathrm{A}$ in Figure 16).

The friction force steadily increases to level B (Section A-B in Figure 16) within the transition zone due to the increasing sliding area on the piston with increasing stroke. 
When all particle chains along the entire radius are in the sliding regime and the migration process of particles is finished, the friction force (Section B-D in Figure 16) is generated by the MR damper $[27,28]$.

This physical interpretation of the observed force response was confirmed by rheometer tests on MR fluid samples [29]. Compression behavior is much less sensitive to the slip effect, since the compensation circuit in this phase is not subject to cavitation.

As the current intensity increased, the cycle became increasingly deformed (Figure 17a,b). Analyzing the F-S plot obtained at $0.5 \mathrm{~Hz}$ (Figure 17a), it is noted that the response of the MR device changed when the power supply for the magnetic circuit exceeded $0.3 \mathrm{~A}$; in the last part of the rebound stroke, damping forces seem to agree with the F-S curve of a standard device. As a result, the increase in the supply current of the magnetic circuit causes, during the extension phase, the displacement of point $B$ (Figure 15) toward the reversal stroke point; when this current is $1.8 \mathrm{~A}$, the point of damping force restoring, in essence, coincides with the beginning of the compression phase.

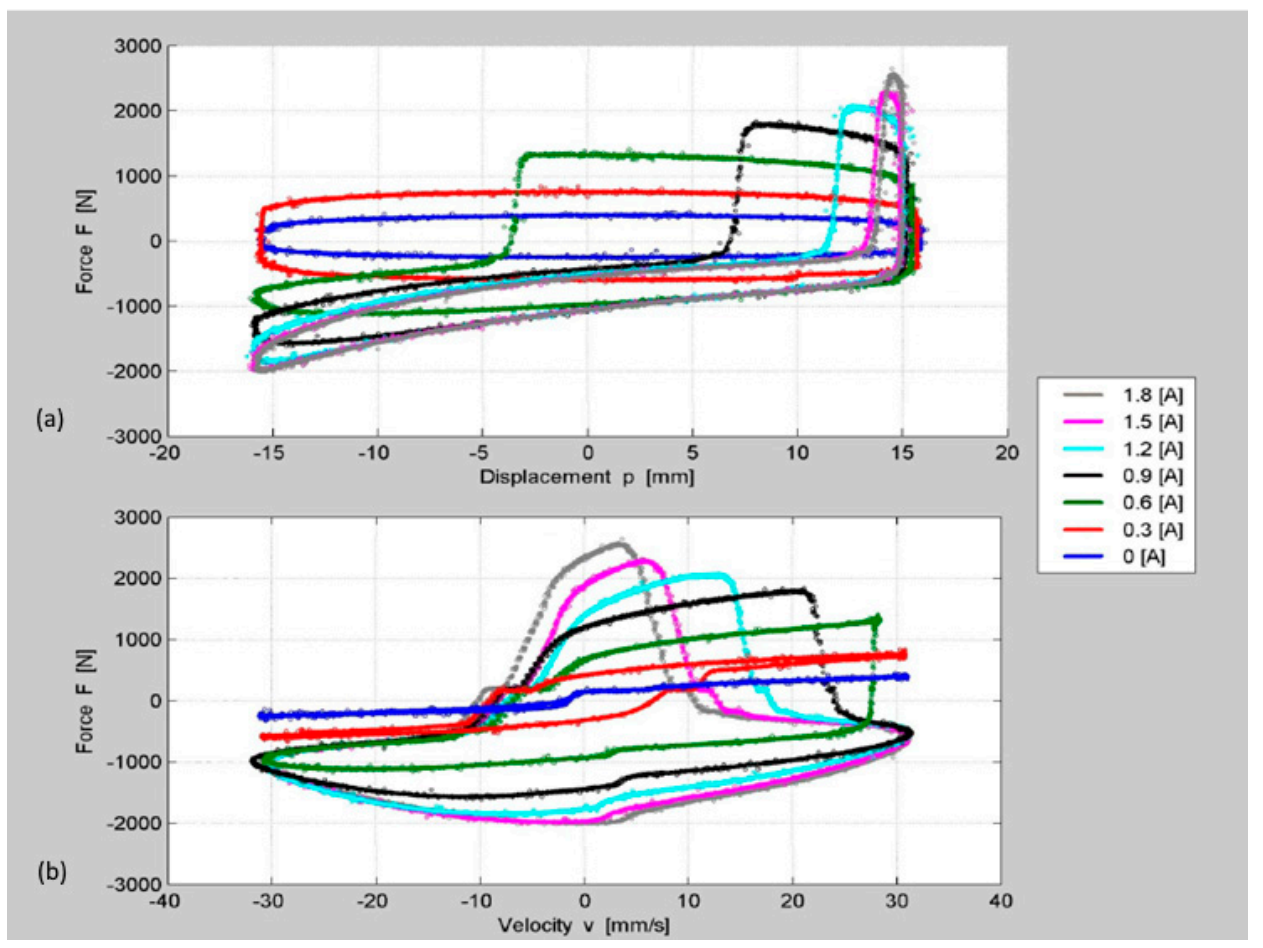

Figure 17. MR shock absorber behavior at $0.5[\mathrm{~Hz}]$, varying current intensity (a) F-S; (b) F-V.

A different shape from the usual one of a traditional shock absorber one can also be noted in the F-V curve (Figure 17b), on which the same reference points used can still be traced. It is well known that the maxima of damping force, both in compression and rebound, consequently tends to move from the extremes of the velocity range (midpoints of the stroke) to the center (stroke reversal points).

If one considers the damping force value in the velocity range under exam $(+32 \mathrm{~mm} / \mathrm{s} /$ $-30.5 \mathrm{~mm} / \mathrm{s}$ ), when varying the current intensity, the values of force exerted increase by a variable quantity from 300 to $500 \mathrm{~N}$, unlike the plate-parallel no slip model. This implies that the model underestimates the experimental data for currents from 0.3 to $1.8 \mathrm{~A}$, unlike what happens at the extremes. Therefore, it is only from 0 to $0.3 \mathrm{~A}$ of input current that the quasi-static parallel no-slip model can be considered descriptive (Figure 17a,b).

The experimental tests show how the hysteretic behavior is highly frequency-dependent: F-V performance correlation between the model and the experimental tests (Figure 18) when varying the forcing frequency becomes much more evident. 


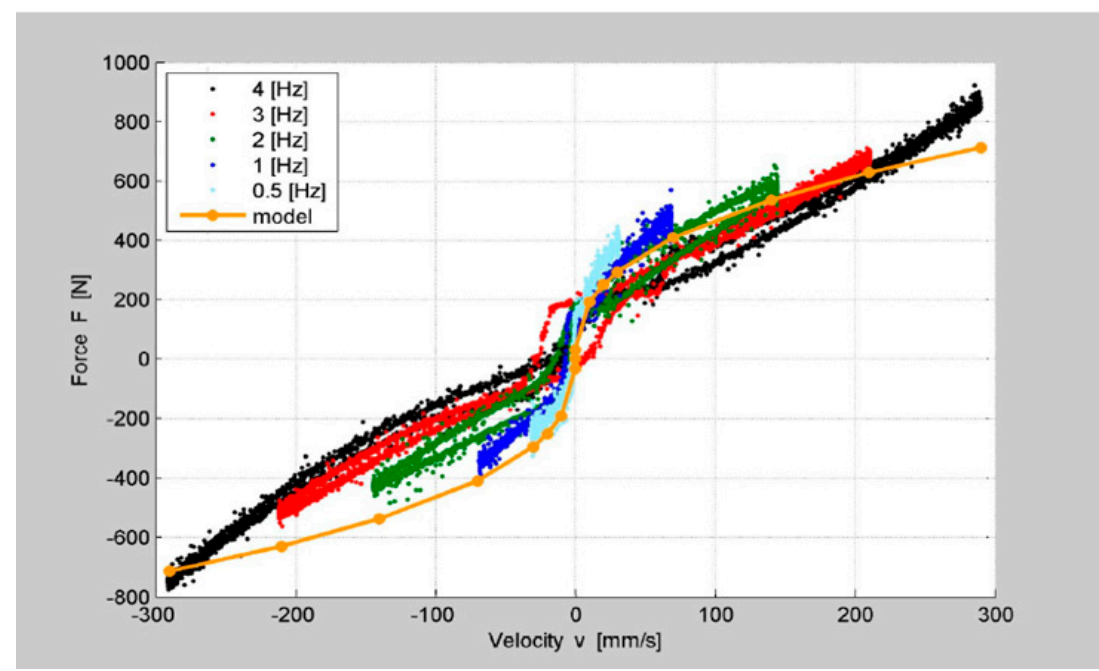

Figure 18. Graph F-V: comparison between experimental data and model at 0 [A].

Since the plate-parallel model is quasi-static, it is possible to compare only the extreme points of the experimental curves, which correspond to quasi-static behaviors. In fact, the velocity at extremes is closest to the quasi-static condition, being $\mathrm{a}=\mathrm{dv} / \mathrm{dt}=0$.

It is evident that a device with the aforementioned dynamic characteristics essentially becomes unusable for vehicle applications; in this regard, it is sufficient to observe that, passing for example from 0.3 to $0.6 \mathrm{~A}$ in the graph F-V (Figure 17a), for a stroke equal to, say, $-10 \mathrm{~mm}$, the damping force changes sign. This proves that the quasi-static parallel model in which the slip prediction is not included proves to be predictive only for low supply currents. The restoring force (point B) can be modeled by a modified Bouc-WenBaber-Nory model [28,29], which considers the slip effect. That given, our intent is to implement a reviewed model to redesign the magnetic circuit of the prototype.

\section{Conclusions}

In order to overcome the limits of the traditional hydraulic shock absorber, a magnetorheological shock absorber has been designed and built, trying to replicate the performance of the reference traditional device. A DA was implemented based on the quasi-static no slip mathematical model of the parallel plate geometry, which is capable of providing the characteristic dimensions of the damper as output. Subsequently, a prototype of a magnetorheological damper has been realized, using a traditional shock absorber as the starting point. The comparison between the experimental and theoretical damping characteristics, with current intensity equal to zero, shows an excellent correspondence. Good correlation is maintained for low current intensities tests. In fact, the current prototype shows good performances only in the context of a reduced stroke, say from -3 to $+5 \mathrm{~mm}$, from 0 to 0.6 A of supply current. As the current intensity increases, the mathematical model tends to overestimate the rebound damping force while underestimating the compression one. Moreover, correlation is strictly dependent on forcing frequency. As the testing velocity and intensity of the current grown up, both the experimental F-S and F-V of the MR device show damping force lacks during both compression and rebound phases. Based on these observations, a review of the DA is in progress, implementing in the calculation both the effect of the slip, according to the Bouc-Wen model [30,31], and the determination of the contribution due to the pressure acting in the compensation tank [32] Furthermore, since it is challenging to match F-D and F-V of the traditional model for a wide range of current intensities, it is planned to develop an algorithm-based non-linear control strategy [33] exploiting the feedback loop.

On balance, the no-slip parallel plate model is slender, since it is almost based on the search for the maximum and minimum damping force obtainable from $\tau 0$, neglecting the transient effects. On the other hand, it is not suitable for demanding dynamical applications, 
making it useful mostly for applications requiring minor adjustments of damping performance. The results of this research could be a useful reference for designers to understand the complexity of the mathematical model to adopt according to the expected performance.

Author Contributions: Formal analysis, D.D.; Methodology, D.D. and L.S.; data curation, D.D. and L.S.; writing-original Draft, D.D.; writing-review \& Editing, D.D. and L.S.; validation, L.S. and G.R.; conceptualization, G.R.; supervision, G.R. All authors have read and agreed to the published version of the manuscript.

Funding: This research received no external funding.

Institutional Review Board Statement: Not applicable.

Informed Consent Statement: Not applicable.

Data Availability Statement: The data presented in this study are available on request from the corresponding author.

Conflicts of Interest: The authors declared no potential conflicts of interest with respect to the research, authorship, and/or publication of this article.

\section{References}

1. Cossalter, V. Motorcycle Dynamics; Race Dynamics: Greendale, WI, USA, 2002.

2. Liguori, C.; Paciello, V.; Paolillo, A.; Pietrosanto, A.; Sommella, P. Characterization of motorcycle suspension systems: Comfort and handling performance evaluation. In Proceedings of the 2013 IEEE International Instrumentation and Measurement Technology Conference (I2MTC), Minneapolis, MN, USA, 6-9 May 2013; pp. 444-449. [CrossRef]

3. Ahmadian, M. Magneto-rheological suspensions for improving ground vehicle's ride comfort, stability, and handling. Veh. Syst. Dyn. 2017, 55, 1618-1642. [CrossRef]

4. Zhu, X.; Jing, X.; Cheng, L. Magnetorheological fluid dampers: A review on structure design and analysis. J. Intell. Mater. Syst. Struct. 2012, 23, 839-873. [CrossRef]

5. Zamani, A.-A.; Tavakoli, S.; Etedali, S.; Sadeghi, J. Modeling of a magneto-rheological damper: An improved multi-statedependent parameter estimation approach. J. Intell. Mater. Syst. Struct. 2019, 30, 1178-1188. [CrossRef]

6. Rabinow, J. The Magnetic Fluid Clutch. Trans. Am. Inst. Electr. Eng. 1948, 67, 1308-1315. [CrossRef]

7. Lam, K.H.; Chen, Z.; Ni, Y.; Chan, H. A magnetorheological damper capable of force and displacement sensing. Sens. Actuators Phys. 2010, 158, 51-59. [CrossRef]

8. Yang, G.; Spencer, B.; Carlson, J.; Sain, M. Large-scale MR fluid dampers: Modeling and dynamic performance considerations. Eng. Struct. 2002, 24, 309-323. [CrossRef]

9. Nguyen, X.B.; Komatsuzaki, T.; Iwata, Y.; Asanuma, H. Modeling and semi-active fuzzy control of magnetorheological elastomerbased isolator for seismic response reduction. Mech. Syst. Signal Process. 2018, 101, 449-466. [CrossRef]

10. Carlson, J. MR fluid technology—commercial status in 2006. In Proceedings of the Electrorheological Fluids and Megnatorheological Suspensions, Lake Tahoe, CA, USA, 18-22 June 2006; pp. 389-395.

11. Wang, D.H.; Wang, T. Principle, design and modeling of an integrated relative displacement self-sensing magnetorheological damper based on electromagnetic induction. Smart Mater. Struct. 2009, 18. [CrossRef]

12. Spelta, C.; Savaresi, S.M.; Fabbri, L. Experimental analysis of a motorcycle semi-active rear suspension. Control. Eng. Pr. 2010, 18, 1239-1250. [CrossRef]

13. Milecki, A.; Hauke, M. Application of magnetorheological fluid in industrial shock absorbers. Mech. Syst. Signal Process. 2012, 28, 528-541. [CrossRef]

14. Aydar, G.; Wang, X.; Gordaninejad, F. A novel two-way-controllable magneto-rheological fluid damper. Smart Mater. Struct. 2010, 19. [CrossRef]

15. Li, W.; Du, H.; Guo, N.Q. Design and testing of an MR steering damper for motorcycles. Int. J. Adv. Manuf. Technol. 2003, 22, 288-294. [CrossRef]

16. Zhang, H.H.; Liao, C.R.; Yu, M.; Huang, S.L. A study of an inner bypass magneto-rheological damper with magnetic bias. Smart Mater. Struct. 2007, 16, N40-N46. [CrossRef]

17. Wang, D.H.; Wang, T.; Bai, X.X.; Yuan, G.; Liao, W.H. A self-sensing magnetorheological shock absorber for motorcycles. In Proceedings of the 19th International Conference on Adaptive Structures and Technologies, Ascona, Switzerland, 6-9 October 2008; pp. 639-649.

18. Metered, H.; Bonello, P.; Oyadiji, S.O. The experimental identification of magnetorheological dampers and evaluation of their controllers. Mech. Syst. Signal Process. 2010, 24, 976-994. [CrossRef]

19. Sun, S.S.; Ning, D.H.; Yang, J.; Du, H.; Zhang, S.; Li, W.H. A seat suspension with a rotary magnetorheological damper for heavy duty vehicles. Smart Mater. Struct. 2016, 25, 105032. [CrossRef]

20. Chen, C.; Liao, W.-H. A self-sensing magnetorheological damper with power generation. Smart Mater. Struct. 2012, 21. [CrossRef] 
21. Zeinali, M. Design and Optimization of Innovative Magnetorheological Damper with Low Temperature. Ph.D. Thesis, Universiti Teknologi Malaysia, Johor, Malaysia, 2015.

22. Kamath, G.M.; Hurt, M.K.; Wereley, N.M. Analysis and testing of Bingham plastic behavior in semi-active electrorheological fluid dampers. Smart Mater. Struct. 1996, 5, 576-590. [CrossRef]

23. Strecker, Z.; Roupec, J.; Mazůrek, I.; Machacek, O.; Kubik, M.; Klapka, M. Design of magnetorheological damper with short time response. J. Intell. Mater. Syst. Struct. 2015, 26, 1951-1958. [CrossRef]

24. Lord, T. Designing with MR Fluids; Lord Corporation Engineering Note; Research Center: Cary, NC, USA, 1999.

25. Yang, B.; Luo, J.; Dong, L. Magnetic circuit FEM analysis and optimum design for MR damper. Int. J. Appl. Electromagn. Mech. 2010, 33, 207-216. [CrossRef]

26. Beskhyroun, S.; Wegner, L.D.; Sparling, B.F. Integral resonant control scheme for cancelling human-induced vibrations in light-weight pedestrian structures. Struct. Control Health Monit. 2011. [CrossRef]

27. BuildoTech Magazine India, New Trends in Smart Elevators, BuildoTech. 2013. Available online: http:/ / buildotechindia.com/ new-trends-in-smart-elevators/ (accessed on 15 December 2013).

28. Laun, H.M.; Schmidt, G.; Gabriel, C.; Kieburg, C. Reliable plate-plate MRF magnetorheometry based on validated radial magnetic flux density profile simulations. Rheol. Acta 2008, 47, 1049-1059. [CrossRef]

29. Weber, F.; Boston, C.; Maślanka, M. An adaptive tuned mass damper based on the emulation of positive and negative stiffness with an MR damper. Smart Mater. Struct. 2010, 20. [CrossRef]

30. Baber, T.T.; Noori, M.N. Modeling General Hysteresis Behavior and Random Vibration Application. J. Vib. Acoust. 1986, 108, 411-420. [CrossRef]

31. Jiang, M.; Rui, X.; Zhu, W.; Yang, F.; Zhu, H.; Jiang, R. Parameter sensitivity analysis and optimum model of the magnetorheological damper's Bouc-Wen model. J. Vib. Control. 2020. [CrossRef]

32. Peng, G.; Li, W.; Du, H.; Deng, H.; Alici, G. Modelling and identifying the parameters of a magneto-rheological damper with a force-lag phenomenon. Appl. Math. Model. 2014, 38, 3763-3773. [CrossRef]

33. Trujillo-Franco, L.G.; Silva-Navarro, G.; Beltran-Carbajal, F.; Campos-Mercado, E.; Abundis-Fong, H.F. On-Line Modal Parameter Identification Applied to Linear and Nonlinear Vibration Absorbers. Actuators 2020, 9, 119. [CrossRef] 